\title{
O Desenvolvimento da Flexibilidade do Cálculo Multiplicativo em
}

\author{
Alunos do 3. ${ }^{\circ}$ Ano*
}

\section{The Development of Multiplicative Calculation Flexibility by $3^{\text {rd }}$ Grade

\author{
Students
}

\author{
Sónia Santos ${ }^{* *}$ \\ ORCID iD 0000-0001-6130-6773 \\ Margarida Rodrigues ${ }^{* * *}$ \\ ORCID iD 0000-0003-4658-6281
}

\begin{abstract}
Resumo
Este artigo tem como objetivo compreender o modo como os alunos desenvolvem a flexibilidade de cálculo multiplicativo num contexto de ensino exploratório, pretendendo responder a três questões de investigação: (i) Quais as estratégias usadas pelos alunos quando resolvem tarefas de multiplicação?; (ii) Como evoluem as estratégias usadas pelos alunos?; e (iii) Como é que os alunos usam de forma flexível o cálculo multiplicativo? A investigação insere-se no paradigma interpretativo de natureza qualitativa, tendo sido realizada uma experiência de ensino numa turma de $3 .^{\circ}$ ano. A recolha de dados recorreu às seguintes técnicas: observação participante e recolha documental. $\mathrm{O}$ artigo foca apenas um par de alunos. Os resultados revelam que os alunos utilizaram múltiplas estratégias na resolução das tarefas envolvendo a multiplicação, evoluindo de estratégias aditivas, associadas a sequências de múltiplos, para estratégias multiplicativas, estabelecendo relações numéricas, e usando fatos básicos conhecidos e propriedades da multiplicação. Esta evolução encontra-se associada ao desenvolvimento da flexibilidade do cálculo multiplicativo dos alunos, o qual, inicialmente, se encontra ancorado na organização dos objetos em partes iguais, evidenciando, no final da experiência de ensino, uma conexão clara entre a ideia de um mesmo produto ser simbolizado por um elevado número de decomposições multiplicativas, a operação de divisão e a identificação da relação proporcional. O estudo evidencia a inexistência de um paralelismo entre o desenvolvimento de estratégias multiplicativas em situações de cálculo e em situações de proporcionalidade.
\end{abstract}

Palavras-chave: Multiplicação. Estratégias de Cálculo. Ensino Exploratório. Cálculo Flexível.

\begin{abstract}
This article aims to understand how the students develop the multiplicative calculation flexibility in a context of exploratory teaching, answering three research questions: (i) What are the strategies used by students when solving multiplication tasks?; (ii) How do the strategies used by the students evolve?; and (iii) How do the students use

\footnotetext{
* Versão revista e ampliada da comunicação apresentada no XXVIII Seminário de Investigação em Educação Matemática com o título "A flexibilidade de cálculo multiplicativo: Um estudo no $3^{\circ}$ ano".

** Mestre em Educação Matemática na Educação Pré-escolar e nos $1^{\circ}$ e $2^{\circ}$ ciclos do Ensino Básico pela Escola Superior de Educação do Instituto Politécnico de Lisboa (ESELX-IPL). Professora no Agrupamento de Escolas Agualva Mira-Sintra (AEAMS), Sintra, Portugal. Endereço para correspondência: Rua Maria do Carmo Torres n. ${ }^{\circ}$ 1, 7. ${ }^{\circ} \mathrm{C}$, Lisboa, Portugal, CP: 1750-359. E-mail: sonyadeus@ gmail.com.

**** Doutora em Educação (especialidade Didática da Matemática) pela Faculdade de Ciências da Universidade de Lisboa (FCUL). Professora Coordenadora na Escola Superior de Educação do Instituto Politécnico de Lisboa (ESELX-IPL), Lisboa, Portugal. Endereço para correspondência: Campus de Benfica do Instituto Politécnico de Lisboa, Lisboa, Portugal, CP: 1549-003. E-mail: margaridar@eselx.ipl.pt.
} 
the multiplicative calculation in a flexible manner? The investigation adopts a qualitative methodology within an interpretive paradigm having been held a teaching experience in a $3^{\text {rd }}$ grade classroom. The data collection took place through the following techniques: participant observation and documentary collection. The article focuses only one pair of students. The results show that students used multiple strategies to solve tasks involving multiplication, evolving from additive strategies, associated with sequences of multiples, to multiplicative strategies, establishing numerical relationships, and using known basic multiplication facts and properties. This evolution is associated to the development of multiplicative calculation flexibility by the students, which is initially anchored in organizing the objects in equal parts, evidencing, at the end of the teaching experience, a clear connection between the idea of the same product being symbolized by a high number of multiplicative decompositions, the operation of division and the identification of the proportional relationship. The study shows the lack of parallelism between the development of multiplicative strategies in calculation and proportional situations.

Keywords: Multiplication. Calculation Strategies. Exploratory Teaching. Flexible Calculation.

\section{Introdução}

A aprendizagem dos números e das operações constitui um processo complexo para as crianças. Assim, é fundamental que elas conheçam e utilizem relações numéricas nos cálculos que efetuam (NCTM, 2007). Para Heirdsfield e Cooper (2004), a flexibilidade no cálculo mental é vista como o uso de estratégias eficientes que são escolhidas de acordo com as combinações numéricas que inspiram a escolha da estratégia. Threlfall (2009) afirma que a estratégia não é escolhida, defendendo que os alunos chegam à solução através de um processo que envolve uma ligação entre o que reparam nos números apresentados numa dada tarefa e o que eles sabem acerca dos números e das operações.

Nas últimas duas décadas, a investigação incidente no cálculo mental tem focado, sobretudo, as estratégias de cálculo que os alunos utilizam. No entanto, tal como referido por Brocardo (2014), os alunos podem utilizar estratégias de forma mecanizada, sem analisar o contexto da tarefa e os números envolvidos. Daí que seja de fundamental importância desenvolver a flexibilidade de cálculo nos alunos de modo a torná-los proficientes matematicamente (NRC, 2001), sendo que a investigação sobre este tópico tem merecido, recentemente, uma atenção crescente entre os educadores matemáticos (RATHGEBSCHNIERER; GREEN, 2015). Este artigo visa contribuir para o aumento do conhecimento sobre este tópico, que assume especial relevância, incidindo, em particular, no modo como se desenvolve a flexibilidade do cálculo multiplicativo.

A flexibilidade do cálculo multiplicativo é o aspecto central da investigação conduzida pela primeira autora (SANTOS, 2016). Este artigo apresenta parte dessa investigação e tem como objetivo compreender o modo como alunos do $3 .^{\circ}$ ano desenvolvem a flexibilidade de cálculo multiplicativo num contexto de ensino exploratório. Decorrentes deste objetivo, pretendemos responder às seguintes questões: i) Quais as estratégias usadas pelos alunos 
quando resolvem tarefas de multiplicação?; ii) Como evoluem as estratégias usadas pelos alunos? e iii) Como é que os alunos usam de forma flexível o cálculo multiplicativo?

\section{A flexibilidade de cálculo}

Segundo Threlfall (2009), o cálculo mental flexível refere-se ao modo como a utilização de uma estratégia na resolução de um problema específico pode ser afetada pelas características específicas da tarefa, ou pelas características individuais dos alunos ou ainda pelas variáveis contextuais. Foxman e Beishuizen (2002) mencionam a diferença existente na taxa de sucesso dos alunos quando resolvem problemas, distinguindo os problemas envolvendo números em contexto daqueles que não apresentam contexto. Desta forma, concluem que, no segundo caso, a taxa de sucesso é mais reduzida. Além dos contextos, as autoras referem-se, ainda, às características dos números e à estrutura semântica do problema como fatores que podem influenciar o desempenho dos alunos. Podendo ser equacionados como fatores de sucesso na aprendizagem, estes aspectos estão também relacionados com a flexibilidade inerente ao cálculo mental (BUYS, 2001), enquanto cálculo pensado que, pelo uso de estratégias variadas e pessoais, atende às características dos números, ou à natureza semântica do contexto, ao serem estabelecidas relações numéricas e aplicadas propriedades operatórias. O cálculo mental assume-se, assim, como um cálculo intimamente associado ao sentido de número, definido por McIntosh, Reys e Reys (1992) como incluindo os conhecimentos sobre os números e as operações e sobre o seu uso flexível na realização de julgamentos matemáticos e na resolução de problemas.

Usar estratégias de cálculo mental com flexibilidade requer sentido de número e, ao usar uma abordagem de estratégias de cálculo, em vez de se focarem em algoritmos processuais, os alunos têm oportunidades para trabalhar com os números de forma flexível, o que por sua vez, oferece oportunidades para melhorar o seu sentido de número (HARTNETT, 2007, p. 345)

Para resolver um problema, usando o cálculo mental, os alunos podem: (i) lembrar-se de, ou 'saber', um fato numérico; (ii) usar um procedimento de contagem simples, em que a sequência numérica é recitada enquanto mantêm o controle da contagem; (iii) fazer uma representação mental de um método em que usam 'papel e lápis'; e (iv) construir uma sequência de transformações dos números envolvidos no problema para chegarem a uma solução (THRELFALL, 2002). Também em Threlfall (2009), são apresentadas as "estratégias de abordagem" do cálculo mental. Uma estratégia de abordagem em cálculo mental é uma forma geral de cognição matemática utilizada no problema — por exemplo: contar; recordar; aplicar 
um método aprendido; visualizar um processo; ou explorar relações conhecidas entre os números.

A flexibilidade, de acordo com vários autores (HEIRDSFIELD; COOPER, 2004; STAR; NEWTON, 2009), é o conhecimento de múltiplas estratégias e a tendência para escolher a mais eficiente para um dado problema, isto é, a que requer o menor número de passos de cálculo intermediários para chegar ao resultado. Threlfall (2009) apresenta um modelo alternativo ao de escolha de estratégia: o zeroing-in, processo, não totalmente consciente, que, na abordagem ao problema, envolve reparar nos números e, simultaneamente, fazer cálculos exploratórios parciais, até emergir a estratégia e a solução do problema. Tomemos o exemplo do cálculo 12x15 para ilustrar estes dois aspetos, o da abordagem e o da solução.

$\mathrm{Na}$ abordagem ao problema, e dependendo da sua compreensão conceitual e do seu conhecimento dos números, os alunos podem reparar nos números envolvidos no cálculo, estabelecendo relações com outros números: 12 é o dobro de $6 ; 12$ é mais dois do que 10 . O processo de reparar nos números pode conduzir a cálculos exploratórios parciais: $6 \times 15 ; 2 \times 3 \times 15$; 2x15; 10x15. Estes cálculos parciais sugerem o que fazer a seguir: decompor o número 12 num produto (6x2), ou numa soma, pelas ordens $(10+2)$, de modo a facilitar o cálculo.

No que diz respeito à solução do problema, os alunos relacionam os números e as operações, usando as suas propriedades. Assim, a estratégia da decomposição num produto associada à relação entre 12 e 6 e ao uso da propriedade associativa da multiplicação permite alcançar a solução: $6 \times 2 \times 15$. E a estratégia da decomposição numa soma associada à relação entre 12 e 10 e ao uso da propriedade distributiva da multiplicação em relação à adição será construída simultaneamente ao alcançar da solução: 10x15+2x15. Na perspetiva de Threlfall (2009), sendo também a adotada no presente estudo, as estratégias de cálculo não são selecionadas e aplicadas, mas sim construídas, ao mesmo tempo que os alunos alcançam a solução do problema. Isto é, as estratégias são emergentes do processo de zeroing-in. A flexibilidade de cálculo encontra-se, pois, associada ao conhecimento dos alunos e ao modo como as estratégias são afetadas pelos números envolvidos nas tarefas e pela rede de relações numéricas e operatórias estabelecidas.

\subsection{A multiplicação e as estratégias de cálculo}

A aprendizagem da multiplicação deve ser feita numa perspectiva de desenvolvimento de sentido de número (MENDES; BROCARDO; OLIVEIRA, 2013). Tal como o sentido de número se desenvolve de forma progressiva, também a aprendizagem da multiplicação se 
processa gradualmente para que os alunos construam estratégias cada vez mais sofisticadas na resolução de problemas. Fosnot e Dolk (2001) alegam que as propriedades são "grandes ideias" associadas à multiplicação, sendo importante usar estratégias que as mobilizem.

Partilhando desta perspetiva, Mendes et al. (2013) consideram que existem ideias essenciais associadas à multiplicação: o compreender um grupo como uma unidade (unitizing); a propriedade distributiva da multiplicação, em relação à adição e à subtração; a propriedade comutativa da multiplicação; os padrões de valor de posição associados à multiplicação por dez e a propriedade associativa da multiplicação. Também a interligação entre a multiplicação e a divisão é um aspeto fundamental que não pode ser ignorado. McIntosh et al. (1992) reiteram que ter consciência da relação entre as operações, especificamente, entre a multiplicação e a divisão, é um dos aspetos contemplados no conhecimento e destreza com as operações, componente do sentido de número.

As estratégias de cálculo multiplicativo pressupõem, assim, a mobilização das propriedades da multiplicação e o estabelecimento de relações numéricas. Estudos empíricos incidentes neste domínio têm documentado uma extensa categorização de estratégias de cálculo multiplicativo. De acordo com diversos autores (BAEK, 2006; FOXMAN; BEISHUIZEN, 2002; HARTNETT, 2007; MULLIGAN; MITCHELMORE, 1997), os alunos, ao longo da aprendizagem da multiplicação, evidenciam a aplicação de diferentes estratégias de cálculo, como por exemplo: (i) contagem envolvendo saltos dos múltiplos (por exemplo, 2, 4, 6, 8, $10, \ldots$ ); (ii) adição repetida (adição sucessiva do mesmo número); (iii) cálculo da divisão (como operação inversa da multiplicação); (iv) partição de números em produtos/em somas (decomposição do multiplicador ou do multiplicando, ou de ambos, estando subjacente o uso da propriedade associativa, no caso da decomposição em produtos, ou da propriedade distributiva da multiplicação em relação à adição, no caso da decomposição em somas); (v) compensação com uso de relações multiplicativas entre os fatores (de modo que a alteração efetuada num fator seja compensada, de forma inversa, no outro fator, garantindo, assim, a invariância do produto; por exemplo, $3 \times 8=24 ; 6 \times 4=24 ; 6$ é dobro de 3 e 4 é metade de 8); (vi) uso complexo de dobros (composição do multiplicador a partir de dobros sucessivos do multiplicando usando, implicitamente, as propriedades associativa e distributiva da multiplicação em relação à adição); e (vii) troca da ordem dos fatores (para obter um produto parcial que facilite o restante cálculo, estando subjacente o uso da propriedade comutativa). $\mathrm{O}$ uso destas estratégias permite aos alunos usarem fatos conhecidos de modo a facilitar o cálculo. As estratégias de contagem e de adição repetida são de natureza aditiva e precedem, no processo de aprendizagem, às restantes de natureza multiplicativa. 
No que diz respeito à fase de transição da adição para a multiplicação, Brocardo, Kraemer, Mendes e Delgado (2017) consideram que a flexibilidade nessa fase se desenvolve ao longo de uma sequência de etapas: (i) produto como representação de alguns números de uma dada quantidade; (ii) o número de vezes como comparação multiplicativa; (iii) o número de vezes como operação emergindo de um arranjo retangular; e (iv) a multiplicidade em conjunção com a divisibilidade e a relação proporcional. Esta sequência justifica-se pelo fato de a flexibilidade requerer a capacidade de operar com produtos e quocientes como objetos matemáticos, usando diferentes simbolismos para o mesmo objeto. Cada uma das etapas decorre da construção cognitiva realizada na etapa anterior.

Como ponto de partida da sequência, os alunos organizam os objetos em partes iguais, estando associado à adição repetida ou à subtração repetida. Em seguida, os alunos comparam as quantidades de forma multiplicativa, emergindo o sentido de fator, assim como a relação inversa (dizer que a Ana tem o dobro do número de cromos do João equivale a afirmar que este tem metade do número de cromos da Ana). Na terceira etapa, as situações que, nas etapas anteriores, se restringiam às situações modeladas por tabelas com sequências de múltiplos, passam a estender-se aos modelos retangulares. A disposição retangular encontra-se associada à comutatividade e à distributividade. Na quarta etapa, os alunos ligam os conhecimentos de natureza fatual, procedimental e conceitual; após descobrirem modos de agrupar os números usando modelos retangulares, os alunos descobrem as equivalências entre as várias decomposições dos produtos.

Relacionando esta sequência com as estratégias atrás categorizadas, podemos afirmar que a primeira etapa envolve estratégias de natureza aditiva; a segunda etapa, ao focar-se na ideia de fator e na relação inversa, constrói as bases para o uso posterior das estratégias de cálculo da divisão e de compensação com uso de relações multiplicativas entre os fatores; a terceira envolve as estratégias de partição de números em somas e de troca de fatores; e a quarta etapa pode envolver as estratégias de cálculo da divisão, de partição de números em produtos, de compensação com uso de relações multiplicativas entre os fatores, de uso complexo de dobros e de troca de fatores. É nesta última etapa que os alunos conseguem lidar com os números como objetos mentais, compondo e decompondo os produtos de muitas maneiras diferentes, fazendo conexões com a divisão e com a relação proporcional existente nas situações multiplicativas (por exemplo, $16 \times 50=50 \times 16$, e este produto está relacionado com 800:16 e 800:50). Segundo Thompson e Saldanha (2003), a conceitualização da multiplicação encerra a multiplicidade, bem como a proporcionalidade.

Focando, em particular, as situações de proporcionalidade presentes nas relações 
multiplicativas, Vergnaud (2014) refere que as mesmas correspondem ao isomorfismo de medidas. Ao lidarem com este tipo de situações, os alunos podem usar estratégias de natureza aditiva (FERNÁNDEZ; LLINARES; VAN DOOREN; DE BOCK; VERSCHAFFEL, 2012) ou multiplicativa (CRAMER; POST, 1993). As estratégias aditivas podem estar baseadas na adição ou subtração repetida no interior de cada uma das variáveis (por exemplo, se 2 cadernos custam 3 euros, 6 cadernos $(2+2+2)$ custam 9 euros $(3+3+3))$, ou na diferença constante, sendo que esta conduz a respostas erradas (por exemplo, se a diferença entre 6 e 2 cadernos é 4, então a diferença de preços também é 4: 6 cadernos custam 7 euros $(3+4)$.

Entre as estratégias multiplicativas, é possível distinguir as estratégias escalares, em que os alunos estabelecem relações entre os valores das mesmas grandezas, e as funcionais, em que as relações são estabelecidas entre as duas grandezas distintas (VERGNAUD, 2014). Também neste tipo de estratégias para resolver problemas com situações de proporcionalidade, as estratégias aditivas precedem as multiplicativas, tendo Fernández et al. (2012) verificado, nos alunos do $4 .^{\circ}$ para o $6^{\circ}$ ano, um decréscimo de utilização de estratégias aditivas. Os alunos tendem a usar mais as estratégias escalares do que as funcionais (SINGER; KOHN; RESNICK, 1997). O enfoque aqui não são as estratégias usadas pelos alunos para efetuar cálculos multiplicativos, tal como categorizado atrás, mas sim para resolver problemas proporcionais. Por exemplo, um aluno pode utilizar uma estratégia funcional e usar diferentes estratégias para efetuar o cálculo multiplicativo em causa.

\section{Metodologia de investigação}

Considerando o objetivo de compreender o modo como os alunos desenvolvem a flexibilidade de cálculo multiplicativo num contexto de ensino exploratório, a investigação insere-se no paradigma interpretativo de natureza qualitativa (BOGDAN; BIKLEN, 1994). Trata-se de uma abordagem focada na compreensão dos fenómenos e nos significados dos processos vivenciados pelos participantes do estudo. A investigação seguiu a modalidade de experiência de ensino, a qual teve como objetivo desenvolver, nos alunos, a flexibilidade de cálculo multiplicativo.

\subsection{Contexto}

A experiência de ensino realizou-se numa escola de $1^{\circ}$ ciclo da cidade de Lisboa, mais precisamente numa turma de $3^{\circ}$ ano composta por 24 alunos: 15 rapazes e 9 raparigas. $\mathrm{O}$ artigo 
foca apenas o trabalho de um par de alunos, Tiago e Anabela, que tinham um desempenho razoável a Matemática. Por motivos éticos, esses nomes são fictícios, de modo a garantir o seu anonimato.

A professora da turma praticava um ensino exploratório, visando a aprendizagem a partir do trabalho que os alunos realizam, o que promove a construção de conhecimento e o surgimento de procedimentos matemáticos com significado, desenvolvendo diferentes competências matemáticas. Para Canavarro (2011), uma aula de tipo exploratório inclui quatro fases distintas: a apresentação da tarefa, a exploração, a discussão e a sistematização. Na primeira fase, procede-se à leitura e interpretação do enunciado da tarefa. Na segunda, os alunos trabalham autonomamente em grupos ou em pares. Na fase da discussão, os alunos apresentam as estratégias aplicadas com a finalidade de comparar e confrontar as mesmas. Na última fase, o professor institucionaliza novas aprendizagens matemáticas que decorreram do trabalho desenvolvido.

Foi implementada uma sequência de seis tarefas, entre 25 de novembro de 2015 e 17 de fevereiro de 2016, na maioria das vezes, com a periodicidade semanal. Relativamente à sua natureza, o grau de desafio é elevado e o grau de estrutura é aberto, permitindo várias possibilidades de resolução (PONTE, 2005). O artigo contempla duas dessas tarefas: a primeira, As espetadas, e as $1^{\mathrm{a}}$ e $2^{\mathrm{a}}$ partes da última tarefa, Pãezinhos I e Pãezinhos II (em anexo). Estas tarefas foram selecionadas por: (i) serem ambas não convencionais na medida em que estão omissos os valores dos fatores envolvidos na operação (BROCARDO et al., 2017), com a apresentação exclusiva do valor correspondente ao produto (61 camarões, em As espetadas, e 800 pãezinhos, em Pãezinhos I), apresentando, assim, uma estrutura similar, embora com diferente ordem de grandeza numérica, que potencia a comparabilidade dos resultados; e (ii) se situarem uma no início e outra no final da sequência, permitindo avaliar a eventual evolução de estratégias ao longo da experiência de ensino e concluir acerca do desenvolvimento da flexibilidade de cálculo. A tarefa Pãezinhos é composta por 4 partes, sendo que a subtarefa Pãezinhos $I$ foi explorada no dia 1 de fevereiro de 2016 e as restantes subtarefas Pãezinhos II, $I I I$ e $I V$ foram exploradas no dia 17 de fevereiro de 2016.

\subsection{Recolha e análise dos dados}

Foram usadas as técnicas de observação participante, com gravação vídeo e áudio do trabalho desenvolvido por dois pares de alunos, bem como da discussão coletiva, e de recolha documental (produções dos alunos). Assim, foram colocados um gravador áudio e uma câmara 
de vídeo, perto de cada um dos pares de alunos, durante a exploração das tarefas, de modo a captar e registar os seus diálogos, ações e trabalhos realizados na folha de papel. O gravador áudio permitiu cruzar o registo dos diálogos com o registo sonoro dos vídeos, especialmente nas partes em que não se percebia bem o que os alunos diziam na gravação em vídeo. Durante a discussão das tarefas, foi colocada uma câmara de vídeo virada para o quadro, onde os alunos apresentavam as suas resoluções. Segundo Yin (2010, p. 92), a observação participante é "um modo especial de observação na qual o investigador não é meramente um observador passivo", na medida em que participa nas atividades observadas, possibilitando observar e verificar pormenores detectáveis pela sua interação com os participantes da investigação.

Para proceder à análise de dados relativa à flexibilidade de cálculo, foram usadas categorias analíticas disjuntas provenientes do quadro teórico de Threlfall (2009) que se apresentam em seguida (Quadro 1). As respetivas subcategorias estão relacionadas entre si já que os alunos, enquanto reparam nos números, poderão simultaneamente realizar cálculos exploratórios parciais, e, por outro lado, ao relacionarem as operações, poderão estar simultaneamente a relacionar os números envolvidos nessas operações.

\begin{tabular}{|l|l|l|}
\hline \multicolumn{1}{|c|}{ Categorias } & \multicolumn{1}{|c|}{ Subcategorias } & \multicolumn{1}{c|}{ Descrição } \\
\hline \multirow{2}{*}{$\begin{array}{l}\text { Abordagem ao } \\
\text { problema }\end{array}$} & Processo de reparar & $\begin{array}{l}\text { Reparar nos números e nas relações que se podem estabelecer } \\
\text { entre eles. }\end{array}$ \\
\cline { 2 - 3 } & $\begin{array}{l}\text { Cálculos exploratórios } \\
\text { parciais }\end{array}$ & $\begin{array}{l}\text { Os cálculos exploratórios parciais decorrem do conhecimento } \\
\text { pessoal dos alunos acerca dos números e das propriedades das } \\
\text { operações quando este é usado para derivar. }\end{array}$ \\
\hline $\begin{array}{l}\text { Solução do } \\
\text { problema }\end{array}$ & Relações estabelecidas & $\begin{array}{l}\text { O modo de relacionar os números para resolver o problema e } \\
\text { alcançar a solução. }\end{array}$ \\
\cline { 2 - 3 } & $\begin{array}{l}\text { Métodos/procedimentos } \\
\text { de cálculo }\end{array}$ & $\begin{array}{l}\text { O modo de relacionar as operações e usar as suas propriedades } \\
\text { para resolver o problema e alcançar a solução. }\end{array}$ \\
\hline
\end{tabular}

Quadro 1 - Categorias analíticas no âmbito da flexibilidade de cálculo Fonte: Elaborado pelas autoras

Focando, em particular, as estratégias de resolução de situações multiplicativas, foram consideradas categorias analíticas relacionadas com as estratégias usadas em cálculos multiplicativos (BAEK, 2006; FOSNOT; DOLK, 2001; FOXMAN; BEISHUIZEN, 2002; HARTNETT, 2007; MULLIGAN; MITCHELMORE, 1997) e em situações de proporcionalidade (CRAMER; POST, 1993; FERNÁNDEZ et al., 2012; VERGNAUD, 2014).

\begin{tabular}{|l|l|}
\hline \multicolumn{1}{|c|}{ Categorias } & \multicolumn{1}{c|}{ Subcategorias } \\
\hline \multirow{4}{*}{$\begin{array}{l}\text { Estratégias aditivas para resolver cálculos } \\
\text { multiplicativos }\end{array}$} & Contagem unitária \\
\cline { 2 - 2 } & Contagem envolvendo saltos dos múltiplos \\
\cline { 2 - 2 } & Adição repetida \\
\cline { 2 - 2 } $\begin{array}{l}\text { Estratégias multiplicativas para resolver cálculos } \\
\text { multiplicativos }\end{array}$ & Uso de dobros (ex.: 4+4=8) \\
\cline { 2 - 2 } & Cálculo da divisão \\
\cline { 2 - 2 } & Partição de números em produtos \\
\cline { 2 - 2 } & $\begin{array}{l}\text { Partição de números em somas } \\
\text { Compensação com uso de relações multiplicativas } \\
\text { entre os fatores }\end{array}$ \\
\hline
\end{tabular}




\begin{tabular}{|l|l|}
\hline \multirow{2}{*}{} & $\begin{array}{l}\text { Compensação no produto após arredondamento de } \\
\text { um fator }\end{array}$ \\
\cline { 2 - 2 } & Uso complexo de dobros \\
\cline { 2 - 2 } & Troca da ordem dos fatores \\
\hline \multirow{2}{*}{$\begin{array}{l}\text { Estratégias aditivas para lidar com situações de } \\
\text { proporcionalidade }\end{array}$} & Adição ou subtração repetida \\
\cline { 2 - 2 } $\begin{array}{l}\text { Estratégias multiplicativas para lidar com situações de } \\
\text { proporcionalidade }\end{array}$ & Diferença constante \\
\cline { 2 - 2 } & Escalar \\
\hline
\end{tabular}

Quadro 2 - Categorias analíticas das estratégias de resolução de situações multiplicativas Fonte: Elaborado pelas autoras

A análise destas estratégias, segundo a categorização apresentada no Quadro 2, foi cruzada com as categorias analíticas apresentadas no Quadro 1, pois cada uma pode ser analisada do ponto de vista da abordagem usada e também do modo de alcançar a solução. Foi, ainda, cruzada, com as etapas definidas por Brocardo et al. (2017) no âmbito de uma sequência de desenvolvimento da flexibilidade no raciocínio multiplicativo.

\section{A exploração e discussão das tarefas}

\subsection{Tarefa "As espetadas"}

O par iniciou o seu trabalho, construindo diferentes tabelas, aplicando a estratégia da contagem envolvendo saltos dos múltiplos. Assim, assumindo a sobra de um camarão, pensaram em divisores de 60, iniciando os saltos a partir de cada um deles, ou seja, iniciaram as tabelas com números de camarões por pauzinho cuja iteração atingia o 60 . As tabelas foram construídas pela seguinte ordem: 5 (Figura 1), 10 (Figura 2), 6 e 4.

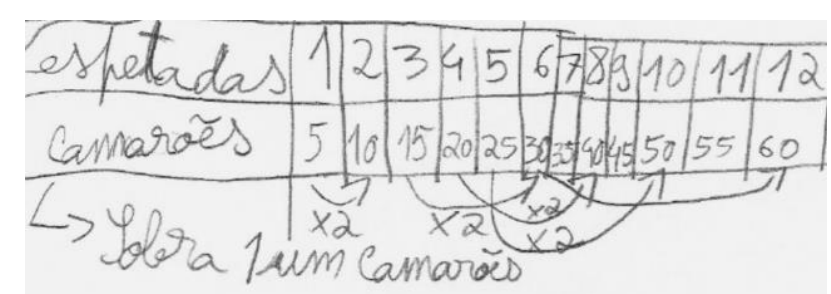

Figura 1 - Cálculo de 5 em 5

Fonte: Produção dos alunos, 2015.

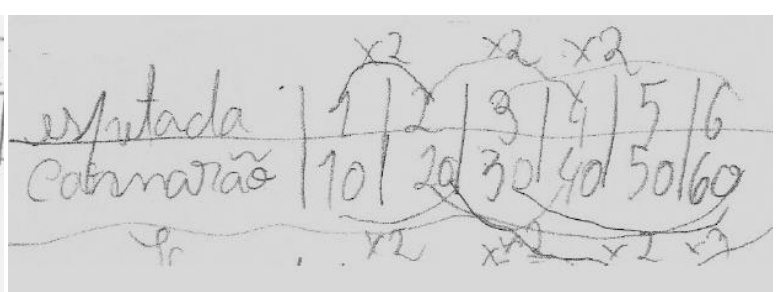

Figura 2 - Cálculo de 10 em 10 Fonte: Produção dos alunos, 2015.

Os alunos identificaram relações numéricas, assinalando alguns dobros existentes na linha inferior da tabela (Figura 1) e nas duas linhas (Figura 2). Seguidamente, o par elaborou outras tabelas envolvendo um número superior de sobras: de 11 em 11 ("sobram 6"), e de 9 em 9 ("sobraram 7 camarões"). Por fim, realizou a tabela do 30, divisor de 60.

Em determinado momento, os alunos usaram a estratégia da troca da ordem dos fatores. Os cálculos presentes na figura 3 tiveram como ponto de partida a tabela do 30 , tendo os alunos redigido "é igual" por cima da tabela e abaixo dos cálculos. Esta expressão evidencia o uso da 
propriedade comutativa para gerar mais uma possibilidade: a tabela indicava 2 espetadas com 30 camarões cada (expresso depois por " $2 \times 30=60 "$ ) e a troca dos fatores originou 30 espetadas com 2 camarões cada ("30x2=60"). Usando a mesma estratégia, os alunos apresentam as possibilidades correspondentes ao total de 61 camarões, sem sobras, ignorando se esta situação faria, ou não, sentido no contexto real.

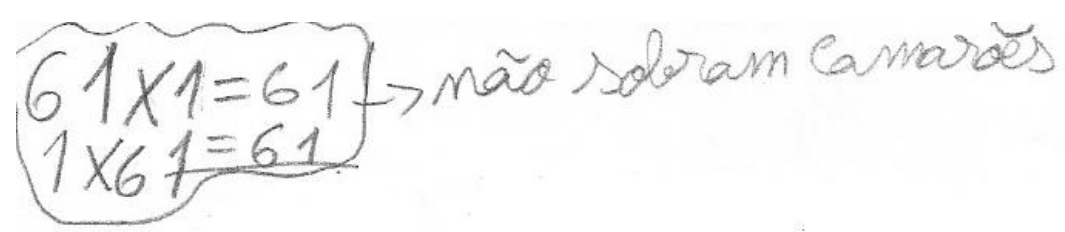

Figura 3 - Estratégia da troca da ordem dos fatores Fonte: Produção dos alunos, 2015.

A troca dos fatores foi também usada a partir das tabelas do 4 e do 9 e, num caso em que não apresentaram tabela, "7x8=56;8x7=56; sobraram 5 camarões". Neste momento, os alunos parecem focar-se nos produtos, distanciando-se da abordagem aditiva inicial. No final, observaram a relação existente entre as tabelas construídas do 5 e do 10, escrevendo a seguinte conclusão: “A tabuada do 10 está relacionada com a tabuada do 5 porque 10 é o dobro de 5 e 5 é metade de $10 "$ ".

Mais tarde, a professora da turma solicitou aos dois elementos do par que fossem ao quadro explicar os cálculos realizados. Tiago explicou o cálculo de 10 em 10 (Figura 4): "Andei a fazer uma tabela e fiz os dobros e as metades e agora percebi que tenho aqui 6 vezes um 10 que está aqui e dá 60. Fiz 10x6=60" (Gravação áudio-visual, 2015). O aluno fez a leitura de que 6 pauzinhos com 10 camarões perfazem 60, registando, por cima da tabela, a troca da ordem dos fatores que gera 10 espetadas com 6 camarões cada. Nesta tabela, Tiago assinalou a relação numérica de dobro tanto na linha superior referente ao número de pauzinhos, como na linha inferior referente ao número de camarões.

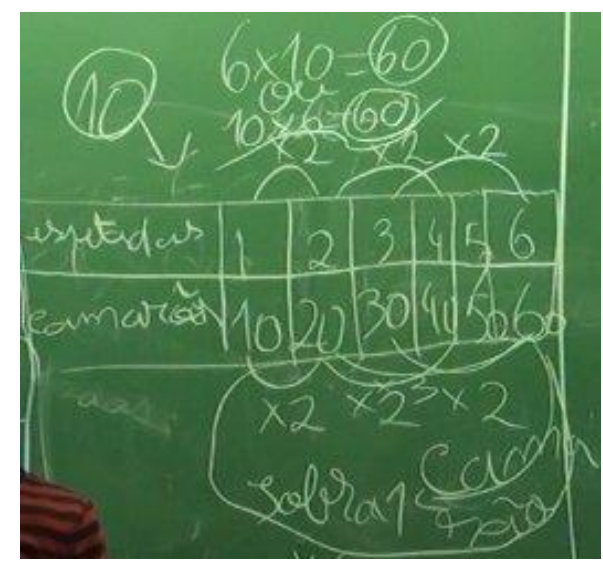

Figura 4 - Explicitação do cálculo de 10 em 10, pelo Tiago Fonte: Arquivo da investigadora, 2015. 
Também Anabela, ao apresentar a tabela do 6, assinalou a relação numérica de dobro entre os números listados em ambas as linhas. A aluna, instada pela professora, relacionou ainda esta tabela com a do 12 ("Porque 6 é metade de 12"), concluindo, no final, que "em vez de fazer a tabela, podia ter usado a multiplicação" (Gravação áudio-visual, 2015).

\subsection{Subtarefa "Pãezinhos I"}

Após a construção de uma tabela com duas colunas: a primeira referente aos tabuleiros e a segunda aos pãezinhos, o Tiago sugeriu a primeira hipótese, tendo chegado a esta através da estratégia da divisão como operação inversa da multiplicação, revelando assim um raciocínio funcional: "800 a dividir por 10? Dá 8. Tem de ser 8x100, 800 a dividir por 100" (Gravação de vídeo, 2016). Apesar de verbalizar 10, Tiago parece ter pensado sempre em 100 ("800 a dividir por $100 ")$.

Na sua abordagem inicial, os alunos pensaram em múltiplas decomposições do $800 \mathrm{em}$ produtos de dois fatores, sem pensar se as mesmas fariam ou não sentido no contexto do problema: 800x1; 100x8; 400x2;8x100. Ou seja, pensaram de um modo abstrato. Após o comentário da professora chamando a atenção para o contexto, os alunos apagaram as possibilidades que já tinham na tabela e decidiram trocar a ordem dos fatores das mesmas, colocando tabuleiros que levassem uma grande quantidade de pãezinhos - "tem de ser os números mais pequeninos em tabuleiros" (Gravação áudio-visual, 2016) -, atendendo a que numa padaria existiria a preocupação de maximizar a ocupação do forno.

Tiago descobriu uma nova possibilidade e comunicou-a à colega: "Olha, arranjei outra conta... 50x16. 50x4 dá 200; 50x8 dá 400, o que quer dizer 50x16" (Gravação áudio-visual, 2016). Anabela ficou na dúvida se esta possibilidade estaria correta. O Tiago explicou: "16x50. Se $8 \times 50$ dá 400, o dobro de 8 que é $50 x 16$ dá 800, porque 8 é metade de 16 e dá 400. Quer dizer que pode" (Gravação áudio-visual, 2016). O aluno aplicou a estratégia do uso complexo de dobros, chegando à decomposição do 800 em 50x16 ou 16x50, através da duplicação sucessiva de um fator e do produto. Partindo de um facto básico por si dominado, $50 \times 4=200$, Tiago estabelece mentalmente uma cadeia com relações numéricas, aplicando sucessivamente o dobro no segundo fator e consequentemente no produto (mantendo o 50 constante), até chegar ao produto pretendido de 800 , obtido com $50 \times 16$. Ou seja, o aluno compõe o 16 como uma potência de base dois $(16=4 \times 2 \times 2)$. Tiago revela flexibilidade de cálculo pelo modo como vai estabelecendo a relação numérica de dobro para obter uma nova decomposição do 800, aplicando intuitivamente a propriedade associativa da multiplicação. Durante a explicação, o 
aluno usou a troca da ordem dos fatores.

Seguidamente, o aluno descobriu uma nova possibilidade de distribuição dos pãezinhos: "Já arranjei outra. 20 tabuleiros vezes 40 pãezinhos. $20 \times 4$ dá 80, mais um zero, acrescenta-se um zero" (Gravação áudio-visual, 2016). Verifica-se aqui a utilização da estratégia da compensação com uso de relações multiplicativas, recorrendo a um fato básico, visto que o aluno usou um fato conhecido de multiplicação, o 20x4, para encontrar outra possibilidade de distribuição dos pãezinhos. A regra de acrescentar o zero decorre dos padrões de valor de posição associados à multiplicação por dez (4x10), com compensação no produto.

Os alunos decidiram, depois, aplicar a estratégia da troca da ordem dos fatores em todas as possibilidades que tinham descoberto. O objetivo do par foi obter uma tabela maior que contemplasse a exaustão das soluções matemáticas da decomposição do 800 em produtos de 2 fatores. Nesta fase, o par desligou-se do contexto da tarefa e centrou-se no sentido numérico e a Anabela deixou de escrever "cada um com" na coluna dos pãezinhos (Figura 5). Assim, registam 800 tabuleiros com 1 pão cada, apesar da chamada de atenção da professora de que tal não fazia sentido. Seguiu-se uma intervenção da investigadora.

Investigadora: Diz-me uma coisa. Tu aqui tens 10 tabuleiros que levam 80. Qual é a metade do número de tabuleiros?

Tiago: $5 \times 160$.

(Gravação áudio-visual, 2016).

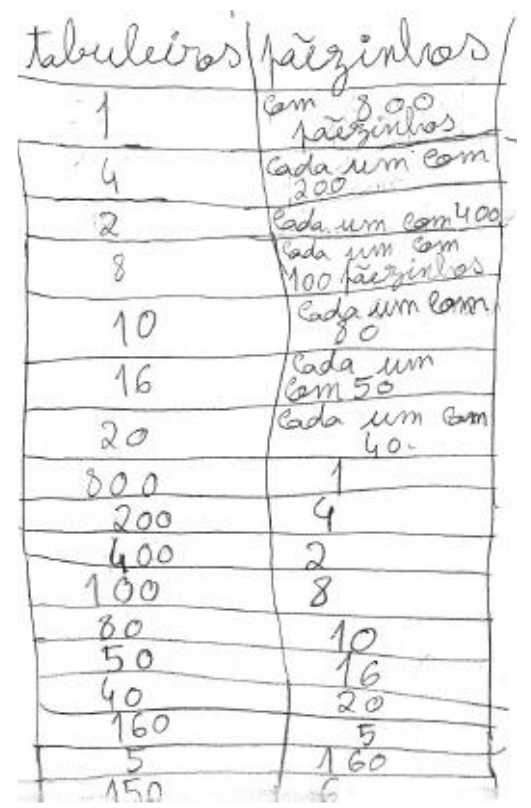

Figura 5 - Tabela da Anabela

Fonte: Produção dos alunos, 2016.

O par escreveu na tabela, porém a Anabela ficou com dúvidas se estaria correto. De forma a mostrar à colega a correção desta possibilidade, o Tiago fez o cálculo na folha, usando a estratégia de partição de números $(100 \times 5=500 ; 60 \times 5=300 ; 500+300=800)$, envolvendo a 
propriedade distributiva da multiplicação em relação à adição. No entanto, inicialmente não foi essa a estratégia usada, mas sim a compensação com uso de relações multiplicativas entre os fatores. Quando a investigadora apela à aplicação da relação de metade do fator 10, Tiago imediatamente aplica a relação de dobro no outro fator, 80, chegando a 5x160.

Tiago observou a tabela e através da estratégia do uso de dobros e metades entre os fatores, chegou ao número 32 como dobro de 16 e ao número 25 como metade de 50 . Assim, o aluno usou a estratégia multiplicativa escalar em cada uma das variáveis, usando intuitivamente um raciocínio proporcional inverso. No entanto, Anabela não registou esta possibilidade na sua tabela.

No momento da discussão coletiva, a professora solicitou ao Tiago que fosse ao quadro.

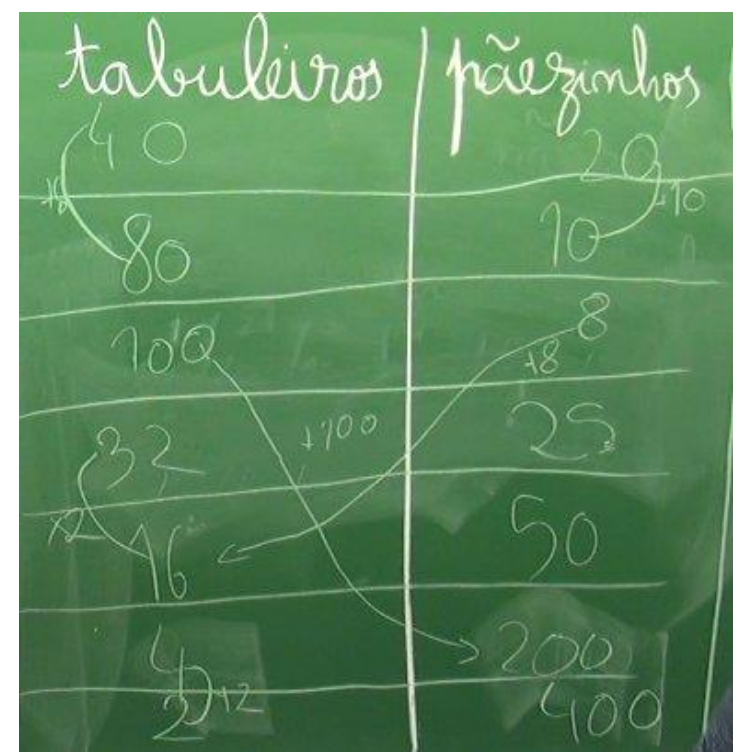

Figura 6 - Apresentação do Tiago

Fonte: Arquivo da investigadora, 2016.

De forma a explicitar a tabela (Figura 6), Tiago assinalou relações numéricas de dobro, explicitando-as, por vezes, de forma aditiva, tanto dentro da variável (por exemplo: "+10"), como entre as duas variáveis (por exemplo: "+100"). No entanto, não explicitou as relações inversas que foram pensadas e usadas durante a exploração da tarefa. Por exemplo, explicitou o 32 como dobro de 16, mas não o 25 como metade de 50. As relações assinaladas são desligadas umas das outras, não evidenciando o raciocínio mobilizado durante a exploração.

Tiago explicou a resposta 2 tabuleiros com 400 pãezinhos da seguinte forma: "Eu tirei o zero do 20 e pus no 40, deu-me 400x2" (Gravação áudio-visual, 2016). Assim, o aluno usou a compensação com uso de relações multiplicativas entre os fatores, ao aplicar uma regra já, por si, dominada, retirando o zero do fator 20 para acrescentar ao fator 40 .

Para justificar as possibilidades de 32 tabuleiros com 25 pãezinhos e 16 tabuleiros com 50 pãezinhos, o aluno usou a partição de números, decompondo em somas ambos os fatores, 
no caso de $32 \times 25$, e apenas o 16, no caso de 16x50 (Figuras 7 e 8).

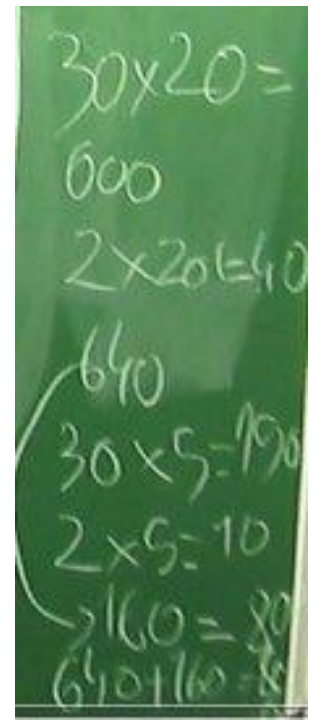

Figura 7 - Partição de números para 32×25 Fonte: Arquivo da investigadora, 2016.

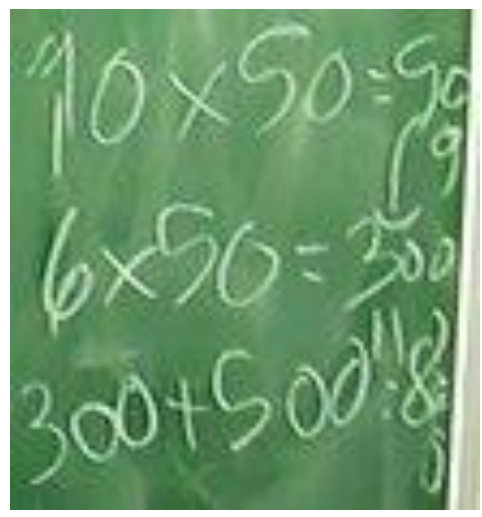

Figura 8 - Partição de números para 16x50 Fonte: Arquivo da investigadora, 2016.

Embora Tiago tenha revelado flexibilidade estratégica ao aplicar relações escalares de dobro e metade entre os fatores, ao explicar à turma as possibilidades encontradas, não consegue, aparentemente, explicar o raciocínio desenvolvido, optando por comprovar as possibilidades obtidas com o procedimento mecanizado de partição de números. O mesmo aconteceu quando, na fase da exploração, o aluno explicou à colega como chegou à possibilidade $5 \times 160$.

\subsection{Subtarefa "Pãezinhos II"}

Os alunos começaram por adicionar o valor das moedas apresentadas no enunciado da tarefa, percebendo que Bernardo tinha pago 70 cêntimos por 5 pãezinhos. Seguidamente, o par calculou $84-70=14$, obtendo o preço de cada pãozinho, 14 cêntimos. Usaram, assim, uma abordagem de natureza aditiva, baseada na subtração repetida.

Mais tarde, Tiago e Anabela optaram por continuar o esquema existente no enunciado da tarefa (Figura 9): 6 pãezinhos custavam 84 cêntimos; 5 pãezinhos custavam 70 cêntimos e assim sucessivamente, mantendo a abordagem anterior de natureza aditiva no interior de cada uma das variáveis, ou seja, subtraindo sempre 14, o valor unitário do preço do pão, ao preço acabado de obter na coluna da direita e subtraindo sempre 1 ao número de pãezinhos, na coluna da esquerda. Contudo, os alunos erraram no cálculo do preço de 4 pãezinhos, o que influenciou os restantes resultados. 


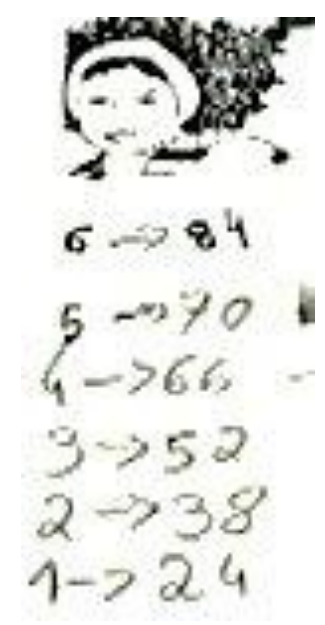

Figura 9 - Esquema presente no enunciado a que os alunos deram continuidade Fonte: Produção dos alunos, 2016.

A professora interveio, visto que Anabela comentou com Tiago que aquele resultado não fazia sentido.

Anabela: Mas isto não tem sentido. Se 1 pãozinho custa isto (apontando para o número 24), 2 pãezinhos só aumenta 14 cêntimos. Não tem sentido nenhum.

Professora: Diz lá, Anabela, diz lá o que tens a dizer.

Anabela: Se este custa 24, porque é que os outros pãezinhos, quando são 2, os pãezinhos custam menos dinheiro cada um?

Professora: Explica lá o teu raciocínio.

Anabela: Têm que ter o mesmo número. Têm de ser todos a 24.

Tiago: Diz mais de 10 cêntimos.

Anabela: Mas os outros pãezinhos também têm de custar 24 assim.

Tiago: Não, não pode ser. Têm de custar 14 cêntimos (...) Tá [sic] mal então.

(Gravação áudio-visual, 2016).

Anabela revela sentido crítico face ao resultado obtido com o esquema, 24 cêntimos por cada pãozinho; porém, não confrontou com a conclusão alcançada anteriormente de 1 pão custar 14 cêntimos e aplicada ao completar o esquema. A aluna questionou a ausência de proporcionalidade que existiria com aqueles preços: "Se 1 pãozinho custa isto (apontando para o número 24), 2 pãezinhos só aumenta 14 cêntimos. Não tem sentido nenhum”. Assim, embora não tenham identificado o seu erro, concluíram que o esquema não estava correto mobilizando um raciocínio proporcional subjacente à situação proposta, o que revela compreensão de que o preço de cada pãozinho tem de ser constante: "Têm que ter o mesmo número. Têm de ser todos a 24". Tiago conclui que o cálculo está errado, pois parte do cálculo inicial conducente ao preço unitário de 14 cêntimos: "Têm de custar 14 cêntimos".

O par decidiu apagar o esquema feito. Tiago recorreu à multiplicação para esclarecer a dúvida do preço de 1 pãozinho. Nesta multiplicação, o aluno utiliza uma relação funcional como forma de verificar se 1 pão custaria 14 cêntimos, tendo aplicado a estratégia da partição de números (Figura 10) no cálculo 14x6. 


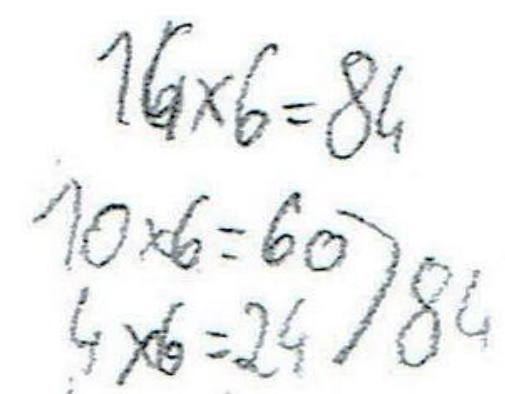

Figura 10 - Estratégia de partição de números (Tiago)

Fonte: Produção dos alunos, 2016.

Assim, Tiago confirma que o seu resultado é igual ao indicado no enunciado como preço de 6 pãezinhos, ficando com a certeza de que o preço unitário é 14 e não 24. Por conseguinte, o erro efetuado levou ao abandono da estratégia escalar aditiva para o uso da estratégia funcional multiplicativa, mais sofisticada do ponto de vista da compreensão conceitual da situação proposta, conferindo certeza acerca do preço unitário do pão.

Anabela decidiu refazer o esquema, mas desta vez de baixo para cima. Ao partir do preço de 1 pãozinho, voltou a usar uma abordagem aditiva, adicionando sempre 14 de forma sucessiva (adição repetida). A aluna errou no cálculo do preço de 3 pãezinhos ao obter 32 (Figura 11). O erro foi detetado pelo Tiago. Após correção do esquema (Figura 12), Anabela usou o cálculo da divisão como operação inversa da multiplicação (Figura 13) para confirmar que 1 pãozinho custava 14 cêntimos.

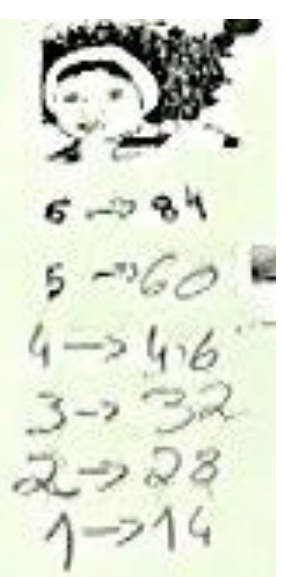

Figura 11 - Erro de cálculo do preço de 3 pãezinhos (Anabela).

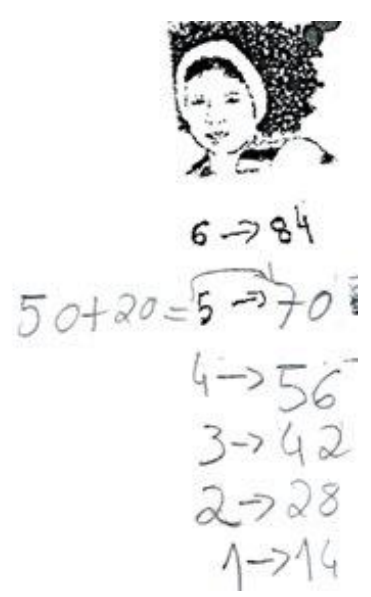

Figura 12 - Esquema correto Fonte: Produção dos alunos, 2016.

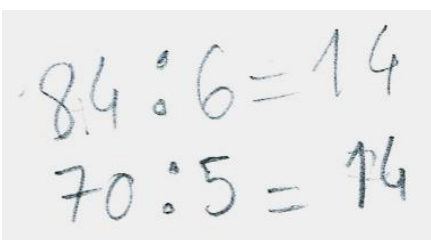

Figura 13 - Cálculo da divisão realizado pela Anabela.

Anabela evolui, assim, para uma abordagem de natureza multiplicativa estabelecendo uma relação funcional entre as variáveis, o preço e o número de pãezinhos, como forma de verificar a constante da proporcionalidade direta.

A conclusão, escrita pelos alunos - "um pãozinho custa 14 cêntimos, porque multiplicámos 14 vezes 6 que nos deu 84 e também dividimos" - apresenta a relação externa funcional entre as variáveis usando ambas as operações, multiplicação (preço = constante x 
número de pãezinhos $)$ e divisão (constante $=$ preço $\div$ número de pãezinhos $)$. Evidencia também a mobilização da relação inversa entre estas duas operações nesta situação.

\subsection{Síntese dos desempenhos nas duas tarefas e evolução das estratégias utilizadas}

Entre as duas tarefas aqui apresentadas, foram implementadas quatro tarefas da sequência nas quais os alunos desenvolveram o conhecimento fatual associado à multiplicação, usando a simbologia da operação de multiplicação para modelar as situações, bem como a capacidade de decomporem os números em produtos e em somas de produtos, exprimindo, neste caso, os produtos através da distributividade, seja em contextos baseados em modelos retangulares, seja apelando ao contexto monetário.

Ambas as tarefas, apresentadas no artigo, contêm situações de proporcionalidade. $\mathrm{Na}$ primeira, o par não aplicou estratégias multiplicativas. Assim, a abordagem inicial dos alunos, ao lidar com este tipo de situações, correspondeu à adoção exclusiva da estratégia aditiva, elaborando tabelas nas quais foram registando os sucessivos resultados da contagem envolvendo saltos dos múltiplos dos diferentes números experimentados.

As tabelas construídas pelo par não traduzem a proporcionalidade inversa presente na tarefa, mas sim a proporcionalidade direta correspondente à sua forma de verificar se os números experimentados atingiam o 60, ou se aproximavam dele. Por exemplo, na tabela correspondente às espetadas com 5 camarões, Tiago e Anabela foram registrando a proporcionalidade direta da variação do número de espetadas mantendo o mesmo número de camarões por espetada: se 1 espetada leva 5 camarões, 2 espetadas levam 10 camarões, ... e 12 espetadas levam um total de 60 camarões.

Embora tenham usado apenas a estratégia aditiva, depois de terem construído as tabelas, os alunos verificaram relações de dobro de natureza escalar, isto é, que se baseiam em relações entre quantidades da mesma natureza/grandeza. Após a conclusão das diferentes tabelas, os alunos exprimem os resultados alcançados através de produtos (expressão funcional da relação de proporcionalidade inversa, $k=x y$ ), aplicando a estratégia da troca da ordem dos fatores para gerar mais possibilidades, e registando também o número de camarões sobrantes: por exemplo, ao concluir a tabela do 4, o par Tiago e Anabela exprimiu essa possibilidade por $15 \times 4=60$, ou seja, 15 espetadas com 4 camarões cada, aplicando logo a situação inversa ao exprimir $4 \times 15=60$, ou seja, 4 espetadas com 15 camarões cada.

Relativamente à última tarefa, o par usou sobretudo estratégias de natureza multiplicativa, recorrendo a cálculos aditivos apenas em casos pontuais. Verifica-se a utilização 
de estratégias de natureza aditiva e multiplicativa no modo como o par lidou com as situações de proporcionalidade presentes. Os alunos usaram a estratégia aditiva no cálculo do preço de 1 pãozinho através da diferença de preços de 6 e de 5 pãezinhos, e na determinação dos restantes preços, em Pãezinhos II.

Usaram a estratégia multiplicativa escalar (relações numéricas no interior de cada uma das variáveis) através da aplicação do dobro numa variável e da metade na outra variável, em Pãezinhos I. A estratégia multiplicativa funcional verifica-se no uso da divisão como operação inversa da multiplicação (i) na compreensão implícita da proporcionalidade inversa presente em Pãezinhos I, e (ii) para verificar a correção do preço de cada pãozinho, na compreensão implícita da proporcionalidade direta presente em Pãezinhos II. O par usou também a estratégia da troca da ordem dos fatores em Pãezinhos I para obter um maior número de decomposições do 800 em produtos de dois fatores.

Nesta última tarefa, os alunos evidenciaram usar as propriedades distributiva, associativa e comutativa, as quais são designadas por Fosnot e Dolk (2001) de "grandes ideias" associadas à multiplicação. Para resolver os cálculos multiplicativos que iam propondo, em Pãezinhos $I$, no sentido de verificar se os mesmos compunham o 800, e assim irem preenchendo a tabela, os alunos aplicaram estratégias de natureza multiplicativa: i) partição de números em somas; ii) compensação com uso de relações multiplicativas entre os fatores; e iii) uso complexo de dobros. Os alunos mostraram, ainda, reparar nos números (por exemplo, o 16, encarado por Tiago, como uma potência de base dois, ao ser gerado pela sucessiva duplicação do fator 2).

A evolução evidenciada pelos alunos ao longo da exploração da subtarefa Pãezinhos II, marcada pela transição da adoção de estratégias aditivas para as de natureza multiplicativa funcional, parece dever-se ao modo como foi concebida a tarefa e simultaneamente aos erros de cálculo aditivo e subtrativo verificados. O enunciado sugere uma abordagem aditiva, ao apresentar os preços de 6 e de 5 pãezinhos. O fato de os preços calculados através dessa abordagem não respeitarem a constante de proporcionalidade levou os alunos a questionarem criticamente os seus resultados e a evoluírem para uma abordagem multiplicativa funcional, verificando o preço de cada pãozinho. Os alunos revelam, também, conhecer e usar a relação existente entre as operações de multiplicação e divisão.

As espetadas e Pãezinhos I lidam com o mesmo tipo de proporcionalidade, mas Pãezinhos $I$ exige lidar com um número com uma ordem de grandeza muito superior. É notória a evolução dos alunos, confrontando o seu desempenho numa e noutra tarefa, para a qual parece ter contribuído significativamente o trabalho realizado durante a exploração das tarefas intermédias da sequência. Em Pãezinhos $I$, os alunos já não usam a estratégia aditiva, revelando 
serem capazes de decompor 800 num elevado número de produtos diferentes, através das relações multiplicativas escalares dentro de cada uma das variáveis, aplicando o dobro numa variável e a metade na outra variável.

\section{Conclusão}

$\mathrm{O}$ estudo aqui apresentado permite concluir que os alunos utilizaram uma grande diversidade de estratégias, durante a resolução de tarefas não convencionais, cuja abertura conduziu-os a explorar um elevado número de possibilidades, geradas mais pelo sentido matemático do que pelo sentido contextual. A comutatividade foi usada pelo par de alunos para registarem novas possibilidades, à revelia de fazer ou não sentido, face ao contexto da tarefa. Essa comutatividade decorreu do conhecimento dos alunos da propriedade comutativa da multiplicação e, simultaneamente, da consciência de que dois pares comutativos correspondem a situações diferenciadas nos contextos das tarefas e que, por isso, têm de ser consideradas.

Confrontando os desempenhos dos alunos nos momentos inicial e final da experiência de ensino, é notória a transição de uma abordagem aditiva (com sequências de múltiplos) para uma de natureza multiplicativa, com uma maior proficiência no uso de relações multiplicativas entre os fatores, ao explorarem as relações escalares, no interior de cada uma das variáveis, interligando a multiplicação, a divisão e a relação proporcional. Diversos autores (BROCARDO et al., 2017; FOSNOT; DOLK, 2001; MENDES et al., 2013; MULLIGAN; MITCHELMORE, 1997) indicam que, inicialmente, os modelos construídos pelos alunos para representar situações multiplicativas estão associados à ideia de multiplicação como adição repetida de parcelas iguais, salientando que na aprendizagem da multiplicação importa desenvolver a passagem do raciocínio aditivo para um de natureza multiplicativa.

Verifica-se desenvolvimento da flexibilidade do cálculo (THRELFALL, 2009) multiplicativo, sobretudo, pela transição da abordagem aditiva para a multiplicativa, parecendo decorrer da implementação da sequência de tarefas ao longo da experiência de ensino, num contexto de ensino exploratório, em que os alunos tiveram oportunidade de progredir ao longo das etapas descritas por Brocardo et al. (2017).

$\mathrm{Na}$ primeira tarefa, os alunos elaboraram tabelas listando saltos de múltiplos. Com as tarefas intermédias, os alunos aprenderam a identificar relações multiplicativas nas tabelas elaboradas, incluindo as inversas, e a usar as propriedades distributiva e comutativa da multiplicação. Assim, esse desenvolvimento fica evidenciado pelo modo proficiente como os alunos atenderam às características dos números e estabeleceram diferentes relações numéricas 
na última tarefa da sequência, dado o alargamento do seu conhecimento numérico, conduzindo à construção de múltiplas estratégias de cálculo, envolvendo números que passam a ser manipulados como objetos matemáticos, ao serem decompostos, compostos, combinados e simbolizados de muitos modos diferentes.

Em suma, tal como sustentado por Brocardo et al. (2017), esse desenvolvimento fica marcado pelo modo como a multiplicação surge em estreita conexão com a divisão e a relação de proporcionalidade e pela integração dos conhecimentos de natureza fatual, procedimental e conceitual. No entanto, os resultados do presente estudo mostram, em particular, que o modo como os alunos utilizam a flexibilidade de cálculo multiplicativo nesta quarta etapa envolve uma multiplicidade de estratégias, tanto aditivas como multiplicativas, no que respeita à forma de lidar com a relação de proporcionalidade. Isto é, o fato de os alunos utilizarem já de um modo consistente e estabilizado estratégias multiplicativas para resolver cálculos multiplicativos não implica que as estratégias para lidar com as situações de proporcionalidade sejam também de natureza multiplicativa. Verificou-se, assim, o uso de estratégias multiplicativas na forma como lidaram com a proporcionalidade inversa em Pãezinhos $I$ e aditivas na abordagem à proporcionalidade direta em Pãezinhos II. Contrariamente ao que é sugerido pela investigação de Fernández et al. (2012), não existe evidência, no presente estudo, de precedência de estratégias aditivas relativamente às multiplicativas, no âmbito dos problemas proporcionais. A natureza destas estratégias parece decorrer do tipo de relação proporcional e das características específicas das subtarefas apresentadas.

É a compreensão intuitiva da relação proporcional, tanto na situação de proporcionalidade inversa como na situação de proporcionalidade direta, que leva os alunos a mobilizarem um raciocínio multiplicativo, gerando novas formas de simbolizar um número através de decomposições multiplicativas, ou a identificarem, por sua iniciativa, erros de cálculo subtrativo, os quais são esclarecidos ou verificados através da multiplicação ou da divisão, numa relação funcional entre as variáveis em causa. Assim, a relação funcional parece assumir uma maior ligação com a consciência, pelos alunos, da relação entre a multiplicação e a divisão, comparativamente à relação escalar.

Por outro lado, do presente estudo, emergem questões que carecem de investigação futura. Focando-nos, especificamente, no caso do uso complexo de dobros, pelo Tiago, verificamos que esta estratégia foi emergindo, tal como descrito por Threlfall (2009), do processo simultâneo de reparar nos números e dos cálculos exploratórios parciais decorrentes do conhecimento individual de fatos básicos da multiplicação, para alcançar a solução de um cálculo desconhecido (50x 16). 
De acordo com o entendimento de flexibilidade de Threlfall (2009), tal significa que Tiago possui flexibilidade de cálculo, evidenciada aqui pela construção desta estratégia, bem como pelas múltiplas relações multiplicativas estabelecidas. O fato de Tiago, na apresentação à turma da sua resolução, no momento de discussão, ter optado por justificar as possibilidades com base no procedimento automatizado de decomposição dos números em somas, que não foi usado durante a exploração autónoma da tarefa, não verbalizando os seus raciocínios multiplicativos flexíveis, pode dever-se a sentir-se mais confiante em mostrar aos colegas a correção dos cálculos multiplicativos através de um procedimento rotineiro com que os alunos da turma já se encontravam bastante familiarizados e cujos resultados estavam legitimados, independentemente dos números envolvidos.

Assim, estes resultados, em particular, sugerem novas direções de investigação. Como garantir a socialização na turma de estratégias construídas individualmente de modo flexível? Que confiança depositam os alunos nas estratégias que constroem, ao nível da respetiva eficiência e credibilidade, nos casos em que essas estratégias assumem alguma singularidade na turma? As dimensões individual e coletiva do processo de desenvolvimento da flexibilidade de cálculo merecem ser investigadas futuramente.

\section{Agradecimentos}

Este artigo enquadra-se no projeto de investigação FLEC_RAC apoiado pelo Instituto Politécnico de Lisboa.

\section{Referências}

BAEK, J. M. Children's mathematical understanding and invented strategies for multidigit multiplication. Teaching Children Mathematics, Reston, v. 12, n. 5, p. 242-247, jan. 2006.

BOGDAN, R.; BIKLEN, S. Investigação qualitativa em educação - Uma introdução à teoria e aos métodos. Tradução de M. J. Alvarez, S. B. Santos, T. M. Baptista. Porto: Porto Editora, 1994.

BROCARDO, J. Exploring flexibility in mental calculation in the domain of multiplicative reasoning. Comunicação apresentada no ECER, Porto, Portugal, 2014.

BROCARDO, J. et al. Tasks to develop flexible multiplicative reasoning. In: CONGRESS OF THE EUROPEAN SOCIETY FOR RESEARCH IN MATHEMATICS EDUCATION, 10., 2017, Dublin. Proceedings of the Tenth Congress of the European Society for Research in Mathematics Education. Dublin: DCU Institute of Education and ERME, 2017. p. 3627-3634.

BUYS, K. Mental arithmetic. In: HEUVEL-PANHUIZEN, M. (Ed.). Children Learn Mathematics: A learning-teaching trajectory with intermediate attainment targets for calculation with whole numbers in primary school. Utrecht: Freudenthal Institute, Utrecht University, 2001. p. 121-146. 
CANAVARRO, A. P. Ensino exploratório da Matemática: Práticas e desafios. Educação e Matemática, Lisboa, n. 115, p. 11-17, nov./dez. 2011.

CRAMER, K.; POST, T. Connecting research to teaching proportional reasoning. Mathematics Teacher, Reston, v. 86, n. 5, p. 404-407, mai. 1993.

FERNÁNDEZ, C. et al. The development of students' use of additive and proportional methods along primary and secondary school. European Journal of Psychology of Education, Heidelberg, v. 27, n. 3, p. 421-438, set. 2012.

FOSNOT, C. T.; DOLK, M. Young mathematicians at work: Constructing multiplication and division. Portsmouth, NH: Heinemann, 2001.

FOXMAN, D.; BEISHUIZEN, M. Mental calculation methods used by 11-year-olds in different attainment bands: A reanalysis of data from the 1987 APU survey in UK. Educational Studies in Mathematics, Dordrecht, v. 51, n. 1-2, p. 41-69, jul. 2002.

HARTNETT, J. Categorisation of mental computation strategies to support teaching and to encourage classroom dialogue. In: CONFERENCE OF THE MATHEMATICS EDUCATION RESEARCH GROUP OF AUSTRALASIA, 30., 2007, Hobart. Proceedings of the 30th annual conference of the Mathematics Education Research Group of Australasia. Hobart: MERGA, 2007. vol. 1. p. 345352.

HEIRDSFIELD, A.; COOPER, T. J. Factors affecting the process of proficient mental addition and subtraction: Case studies of flexible and inflexible computers. The Journal of Mathematical Behavior, New Jersey, v. 23, n. 4, p. 443-463, dez. 2004.

MCINTOSH, A.; REYS, B. J.; REYS, R. E. A proposed framework for examining basic number sense. For the Learning of Mathematics, White Rock, v. 12, n. 3, p. 2-8 e 44, nov. 1992.

MENDES, F.; BROCARDO; J.; OLIVEIRA, H. A evolução dos procedimentos usados pelos alunos: Contributo de uma experiência de ensino centrada na multiplicação. Quadrante, Lisboa, v. 22, n. 1, p. 133-162, jun. 2013.

MULLIGAN, J. T.; MITCHELMORE, M. C. Young children's intuitive models of multiplication and division. Journal for Research in Mathematics Education, Reston, v. 28, n. 3, p. 309-330, mai. 1997.

NATIONAL COUNCIL OF TEACHERS OF MATHEMATICS (NCTM). Princípios e normas para a matemática escolar. Tradução de M. Melo. Lisboa: Associação de Professores de Matemática. 2007.

NATIONAL RESEARCH COUNCIL (NRC). Adding it up: Helping children learn mathematics. KILPATRICK, J.; SWAFFORD, J.; FINDELL, B. (Eds.). Mathematics Learning Study Committee, Center for Education,. Division of Behavioral and Social Sciences and Education. Washington, DC: National Academy Press. 2001.

PONTE, J. P. Gestão curricular em matemática. In: GRUPO DE TRABALHO DE INVESTIGAÇÃO (GTI) (Org.). O professor e o desenvolvimento curricular. Lisboa: Associação de Professores de Matemática, 2005. p. 11-34.

RATHGEB-SCHNIERER, E., GREEN, M. Cognitive flexibility and reasoning patterns in American and German elementary students when sorting addition and subtraction problems. In: CERME, 9., 2015, Prague. Proceedings of the Ninth Congress of the European Society for Research in 
Mathematics Education. Prague: Charles University in Prague, Faculty of Education and ERME, 2015. p. 339-345.

SANTOS, S. A flexibilidade de cálculo multiplicativo num contexto de ensino exploratório. 2016. 116f. Dissertação (Mestrado em Educação Matemática na Educação Pré-escolar e nos $1^{\circ} \mathrm{e} 2^{\circ}$ ciclos do Ensino Básico) - Escola Superior de Educação, Instituto Politécnico de Lisboa, Lisboa, 2016.

SINGER, J. A.; KOHN, A. S.; RESNICK, L. B. Knowing about proportions in different contexts. In: NUNES, T.; BRYANT, P. (Eds.). Learning and teaching mathematics: An international perspective. Hove: Psychology Press, 1997. p. 315-345.

STAR, J. R.; NEWTON, K. J. The nature and development of experts' strategy flexibility for solving equations. ZDM Mathematics Education, Berlim v. 41, n. 5, p. 557-567, out. 2009.

THOMPSON, P. W.; SALDANHA, L. A. Fractions and multiplicative reasoning. In: KILPATRICK, J.; MARTIN, G.; SCHIFTER, D. (Eds.). Research companion to the Principles and Standards for School Mathematics. Reston, VA: National Council of Teachers of Mathematics, 2003. p. 95114.

THRELFALL, J. Flexible mental calculation. Educational Studies in Mathematics, Dordrecht, v. 50, n. 1, p. 29-47, mai. 2002.

THRELFALL, J. Strategies and flexibility in mental calculation. ZDM Mathematics Education, Berlim, v. 41, n. 5, p. 541-555, out. 2009.

VERGNAUD, G. A criança, a matemática e a realidade. Tradução de M. L. F. Moro. Paraná: Editora UFPR, 2014.

YIN, R. K. Estudo de caso: planejamento e métodos. Tradução de D. Grassi. Porto Alegre: Bookman, 2010.

Submetido em 09 de Abril de 2018. Aprovado em 07 de Novembro de 2018. 


\section{Anexo $^{1}$}

\section{As espetadas}

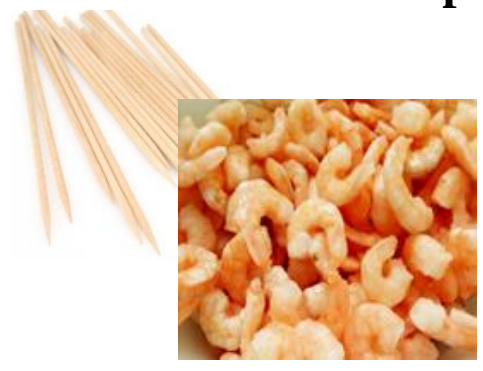

$\ldots 51,52,53,54,56,57,58,59,60,61$ !

O Vasco faz anos. Para a festa quer fazer espetadas com o mesmo número de camarões. A mãe comprou um saco com 61 camarões.

Se estivesses no lugar do Vasco como preparavas as espetadas? Quantas terias de preparar? Porquê?

\section{Pãezinhos I}

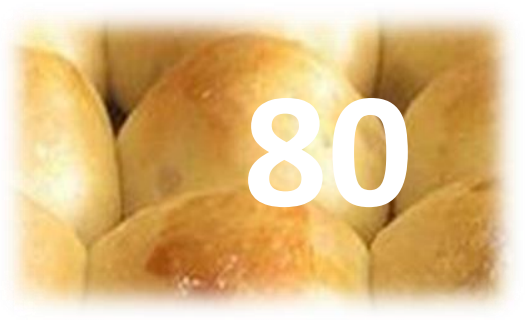

Todos os sábados, o padeiro da padaria Pão Bom cozinha 800 pãezinhos que dispõe em tabuleiros. Tens uma ideia de quantos tabuleiros precisará? Confirma a tua ideia.
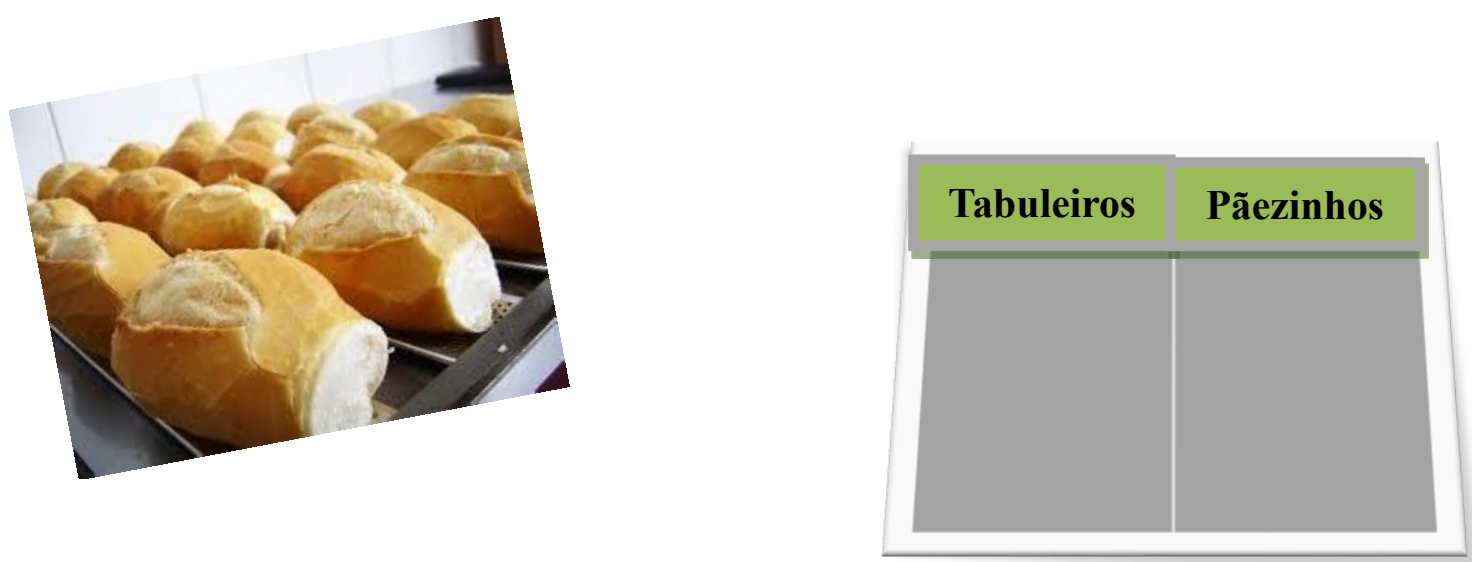

${ }^{1}$ Conceção das tarefas As espetadas, Pãezinhos I e II: Jean Marie Kraemer 


\section{Pãezinhos II}

A Beatriz está na padaria com o seu colega Bernardo. Ela compra seis pãezinhos e paga oitenta e quatro cêntimos.

- Então - pensou Beatriz - um pãozinho custa mais do que 10 cêntimos!

O Bernardo paga os seus cinco pãezinhos com uma moeda de 50 cêntimos e uma de 20 e não recebe troco.

- Ah! - exclama Beatriz - já sei quanto custa cada pãozinho!

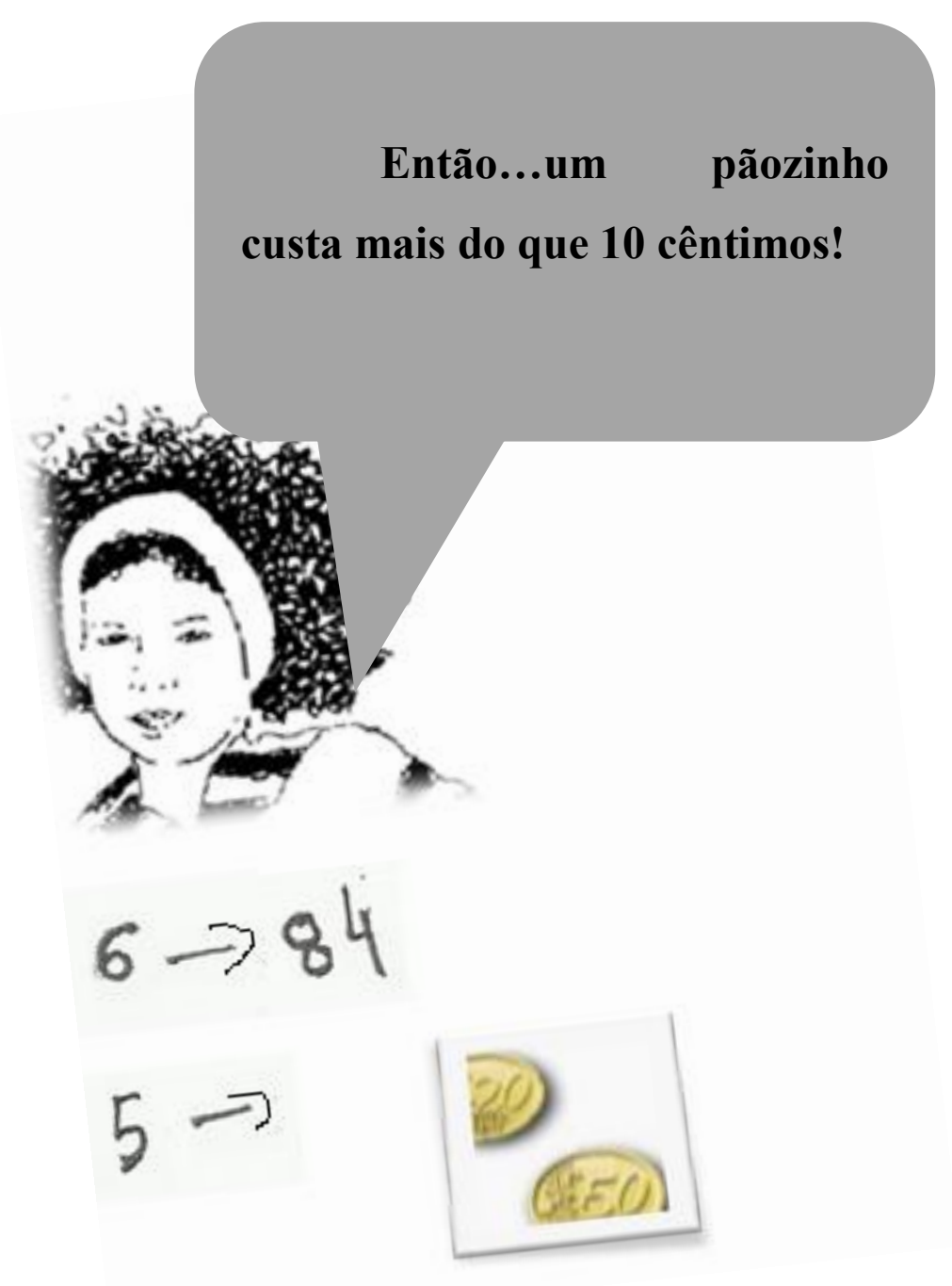

